\title{
PENERAPAN TEKNOLOGI PENGOLAHAN LIMBAH DENGAN BIOREMEDIASI DAN FITOREMEDIASI BAGI PRODUKTIVITAS LAHAN KERING DI SASI, KECAMATAN KEFAMENANU, KABUPATEN TIMOR TENGAH UTARA, NTT
}

\author{
${ }^{1 *}$ Ludgardis Ledheng, ${ }^{2}$ Maria Yustiningsih dan ${ }^{3}$ Anna Tefa \\ ${ }^{1,2}$ Fakultas Ilmu Pendidikan, Universitas Timor \\ ${ }^{3}$ Fakultas Pertanian, Universitas Timor \\ *Email: ludgardisledheng12@gmail.com
}

\begin{abstract}
Abstrak
Industri tahu yang berada di kelurahan Sasi, kecamatan Kefamenanu, kabupaten Timor Tengah Utara, provinsi Nusa Tenggara Timur terletak di tengah tengah pemukiman penduduk. Limbah cair yang dihasilkan menimbulkan masalah bagi pencemaran lingkungan sekitar. Pencegahan yang dilakukan dengan cara mengangkut limbah menggunakan truk kemudian di buang ke tempat lain. Pembuangan limbah cair dibeberapa lahan milik warga tanpa unit pengolahan berdampak pencemaran bahkan berpotensi konflik dengan warga. Kelompok industri tahu sebagai mitra 1 yang didampingi pada Program Kemitraan Masyarakat (PKM) perlu mendapatkan perhatian. Penyediaan tempat penampung limbah pada salah satu lahan warga untuk diolah sebelum dimanfaatkan untuk usaha tani menjadi solusi yang tepat menangani permasalahan limbah industri selama ini. Kelompok tani Oeputi sebagai mitra 2 yang didampingi pada Program Kemitraan Masyarakat, merupakan kelompok tani lahan kering yang usaha taninya sangat bergantung dari curah hujan. Usaha tani musim kemarau umumnya dilakukan di pekarangan rumah. Sedangkan pada musim hujan usaha tani dilakukan di lahan tani. Melihat potensi lahan tani yang cukup luas, dengan limbah cair tahu berlimpah, tentunya dapat meningkatkan produksi tanaman lahan kering di kelurahan Sasi. Oleh sebab itu dibutuhkan metode pengolahan limbah yang ramah lingkungan dan berdampak pada terpenuhinya kebutuhan bagi usaha tani. Dengan metode ini maka luaran yang diharapkan dari kelompok tani Oeputi adalah mampu melakukan pengolahan limbah cair tahu dengan mudah, ramah lingkungan dan dapat memenuhi kebutuhan irigasi maupun pupuk bagi tanaman. Untuk mendukung pelaksanaan teknologi pengolahan limbah ini maka diperlukan seperangkat instalasi pengolahan dan irigasi bagi petani kelompok tani Oeputi. Hasil dari kegiatan PKM ini adalah: (1) Dibangunnya 2 (dua) unit media penampung limbah masing - masing berkapasitas 2500 liter sebagai media tetap pembuangan limbah cair industri tahu di lahan kelompok tani Oeputi. (2) Pelaksanaan pelatihan pengolahan limbah dengan bioremediasi dan fitoremediasi telah memberikan wawasan pengetahuan dan keterampilan untuk mengubah limbah cair menjadi lebih ramah lingkungan dan dapat digunakan sebagai irigasi. Penerapan iptek pada kegiatan PKM ini juga telah berdampak pada perubahan mainset petani disekitar areal industri tahu untuk menjadikan limbah sebagai kebutuhan utama dalam usaha budidaya tanaman dan ternak.
\end{abstract}

Kata Kunci : Limbah, Tahu, Bioremediasi, Fitoremediasi, Lahan kering 
Jurnal SEMAR Vol. 7 No. 2, 2018 hal. $15-22$

ISSN: 2302-3937 | Copyright (C LPPM Universitas Sebelas Maret Homepage: https://jurnal.uns.ac.id/jurnal-semar

\section{PENDAHULUAN}

Limbah cair yang dihasilkan dari kelompok industri tahu, kecamatan Kefamenanu, kabupaten Timor Tengah Utara (TTU), provinsi Nusa Tenggara Timur (NTT), telah melampau kapasitas dan berpotensi mencemari lingkungan. Limbah ini terjadi karena adanya sisa air tahu yang tidak menggumpal dan potongan tahu yang hancur karena proses penggumpalan, serta cairan kekuningan yang dihasilkan dapat menimbulkan bau tidak sedap jika dibiarkan (Nohong, 2010).

Industri tahu ini terletak diantara pemukiman penduduk dengan luas lahan yang terbatas tentunya sulit penanganannya. Letak industri yang jauh dari daerah aliran air memaksa pihak industri tahu mengangkut limbahnya agar dibuang ke tempat lain. Pengangkutan limbah menggunakan truk pengangkut menjadi pilihan yang harus dilakukan. Limbah disedot, dialiri ke truk kemudian di buang ke lahan- lahan tidur milik warga. Pembuangan yang dilakukan terus menerus dibeberapa lahan milik petani tanpa unit pengolahan limbah memberikan dampak pada pencemaran bahkan berpotensi konflik dengan warga. Sebab limbah yang dibuang ke lingkungan harus memenuhi standar baku mutu yang ditetapkan (Darsono, 2007).

Pembuangan limbah pada lahan warga dapat dilihat pada gambar 1.
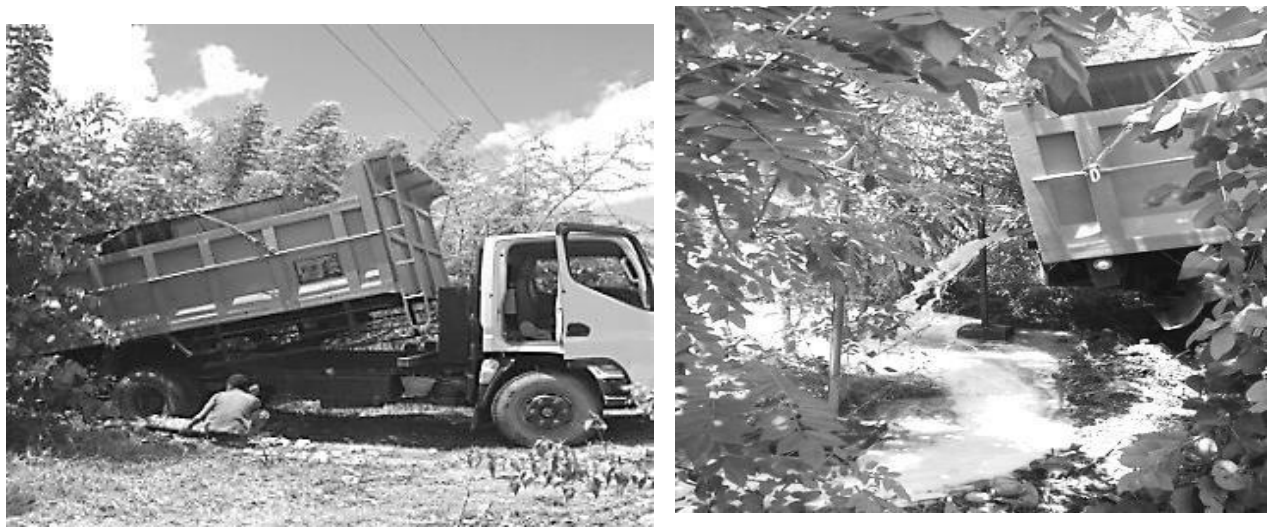

Gambar 1. Pembuangan limbah cair tahu di lahan warga

Menurut Indahwati (2008), selain dapat digunakan sebagai pupuk, limbah cair tahu dapat dimanfaatkan untuk irigasi tanaman. Oleh karena itu bila limbah tahu dijadikan solusi untuk tujuan irigasi pada tanaman, tentunya turut membantu dalam mengoptimalkan kembali lahan yang sering tidak dikelola saat musim kemarau. Seperti yang dirasakan para petani kelompok tani Oeputi sebagai mitra II Program Kemitraan Masyarakat (PKM) yang diusulkan.

Diketahui bahwa klasifikasi mutu limbah cair tahu di wilayah kecamatan Kefamenanu berada pada kelas 4 yakni masih dapat diperuntukkan bagi pengairan tanaman (BLHD kabupaten Timor Tengah Utara, 2016). Namun aroma tidak sedap yang timbul dari limbah tersebut, berpotensi menimbulkan pencemaran udara. Oleh sebab itu dibutuhkan teknologi pengolahan limbah yang mudah, murah, ramah dan berdampak pada terpenuhinya kebutuhan irigasi tanaman. Teknologi yang tepat dalam mengatasi limbah cair tahu pada areal pertanian yakni teknologi bioremediasi pada tahap awal pengolahan dan fitoremediasi pada tahap lanjutan. Bioremediasi merupakan penggunaan mikroorganisme untuk mengurangi pencemaran lingkungan. Enzim-enzim yang diproduksi oleh mikroorganisme memodifikasi polutan beracun dengan mengubah 
struktur kimia polutan, menjadi tidak kompleks atau tidak berbahaya (Sutrisno et al, 2015). Sedangkan fitoremediasi merupakan pengolahan limbah menggunakan tanaman air. Namun adapun faktor yang membatasi penerapan teknologi pengolahan limbah di areal pertanian di antaranya informasi teknologi pengolahan limbah belum menyebar secara menyeluruh ke setiap petani, penguasaan teknologi pengolahan limbah masih lemah dan rendah, terbukti sebagian besar petani belum menerapkan karena belum paham teknis pelaksanaannya (Nasrul Hosen, 2012)

Tujuan pelaksanaan program kemitraan masyarakat adalah : (1) dibangunnya tempat penampungan limbah yang tetap di lahan kelompok tani Oeputi. (2) Penerapan teknologi bioremediasi dan fitoremediasi melalui pelatihan dan pendampingan bagi petani pihak industri maupun petani kelompok tani Oeputi. (3) Pelatihan pembuatan pupuk dari limbah. (4) Membantu memfasilitasi instalasi pengolahan limbah maupun irigasi.

\section{METODE PELAKSANAAN}

Untuk mendapatkan media tampung limbah yang kuat, mudah dalam pemanfaatan serta sesuai untuk kebutuhan pengolahan limbah maka dibuat tahapan pendampingan kerja diantaranya : (1) Penentuan letak bak pada dataran yang lebih tinggi agar mudah membuang limbah dan memanfaatkannya. (2) Penggalian fondasi dan peletakan batu. (3) Perakitan besi dan cor slop fondasi. (4) Pemasangan pipa outlet penghubung media 1 dan 2. (5) Pemasangan tembok media. (6) Pemasangan saringan pada pipa outlet.

Pelaksanaan pelatihan pengolahan limbah dengan bioremediasi dan fitoremediasi dilakukan dengan melibatkan pihak industri tahu. Pelatihan dilakukan dengan metode diskusi dan praktek langsung pada media limbah. Untuk mengukur keberhasilan penerapan ipteks terdapat 2 (dua) indikator tujuan terukur jangka panjang: (1) Tujuan terukur dalam hal penggunaan teknologi bioremediasi dengan menggunakan EM4 yang ditunjukan dengan semua anggota mitra dapat menggunakan EM4 dengan perbandingan yang tepat pada media pengolahan limbah. (2) Tujuan terukur dalam hal penggunaan teknologi fitoremediasi dengan menggunakan tanaman air yang ditunjukan dengan semua anggota kelompok tani Oeputi bisa membudidayakan tanaman air dengan pemilihan tanaman secara tepat.

\section{HASIL DAN PEMBAHASAN Perlakuan Bioremediasi EM 4}

Salah satu pengolahan limbah yang mudah, murah dan cepat yaitu pengolahan limbah secara biologis atau pengolahan dengan memanfaatkan mikroorganisme. Mikroorganisme yang digunakan untuk pengolahan limbah khususnya limbah cair tahu adalah mikroorganisme yang terdapat pada Effective Microorganism - $4\left(\mathrm{EM}_{4}\right)$. Bakteri asam laktat memfermentasi bahan organik menjadi asam laktat yang berfungsi untuk mempercepat perombakan bahan organik dan dibantu oleh jamur fermentasi yang memfermentasi bahan organik menjadi senyawa-senyawa organik yang lebih sederhana. Ada beberapa teknik dasar yang digunakan dalam proses bioremediasi diantaranya aktivitas mikroorganisme $\left(\mathrm{EM}_{4}\right)$.

Perbandingan aktivasi EM4 mengacu pada Sutrisno et al (2015) yakni 1/20 (5\%). Sebanyak 6,2 liter EM4 kemudian diencerkan dengan 118 liter air di dalam drum 150 liter kemudian didiamkan selama 5-7 hari dengan cara ditutup. Proses ini bertujuan untuk mengembangbiakkan mikroorganisme dan mengaktifkan mikroorganisme yang ada pada EM4 dari kondisi dorman sehingga mikroorganisme dapat bekerja dengan efisien dan 
optimal pada saat dicampurkan ke dalam limbah cair tahu.

Setelah didiamkan 7 hari pada tahapan pengenceran, EM4 tersebut telah aktif untuk digunakan dalam proses fermentasi. Sebanyak 124,2 liter EM4 aktif dicampurkan dengan limbah cair 2.368,4 liter didiamkan dengan cara ditutup selama 15 hari. Penutupan bak limbah untuk fermentasi dapat dilihat pada gambar 2.

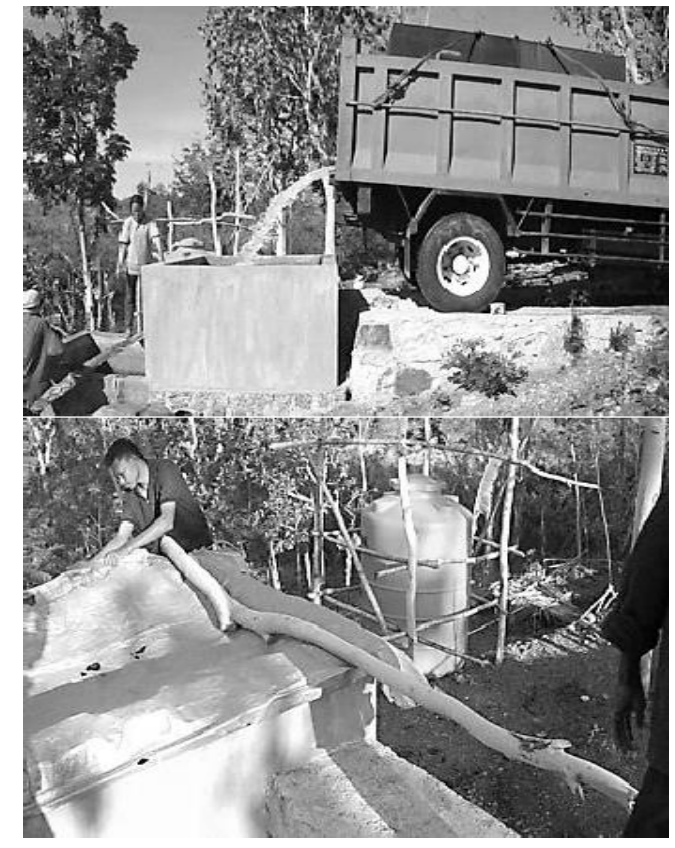

Gambar 2. Penutupan bak untuk proses fermentasi.

\section{Perlakuan Fitoremediasi}

Perlakuan fitoremediasi merupakan perlakuan lanjutan dari bioremediasi EM4. Fitoremediasi dapat didefinisikan sebagai penggunaan tumbuhan untuk menghilangkan bahan pencemar baik itu senyawa organik maupun anorganik. Proses fitoremediasi berlangsung secara alami dengan enam tahap proses secara serial yang dilakukan tumbuhan terhadap zat kontaminan/ pencemar yang berada disekitarnya:

1. Phytoacumulation (phytoextraction) yaitu proses tumbuhan menarik zat kontaminan dari media sehingga berakumulasi disekitar akar tumbuhan.

2. Rhizofiltration (rhizo $=$ akar) adalah proses adsorpsi atau pengedapan zat kontaminan oleh akar untuk menempel pada akar.

3. Phytostabilization yaitu penempelan zat-zat contaminan tertentu pada akar yang tidak mungkin terserap kedalam batang tumbuhan.

4. Rhyzodegradetion yaitu penguraian zat-zat kontaminan oleh aktivitas microba yang berada disekitar akar tumbuhan. Misalnya ragi, fungi dan bacteri.

5. Phytodegradation (phyto transformation) yaitu proses yang dilakukan tumbuhan untuk menguraikan zat kontaminan yang mempunyai rantai molekul yang kompleks menjadi bahan yang tidak berbahaya dengan dengan susunan molekul yang lebih sederhana yang dapat berguna bagi pertumbuhan tumbuhan itu sendiri.

6. Phytovolatization yaitu proses menarik dan transpirasi zat contaminan oleh tumbuhan. Beberapa tumbuhan dapat menguapkan air 200 sampai dengan 1000 
liter per hari untuk setiap batang.

Melalui sistim irigasi kolam (beton) seperti yang diterapkan dalam program kemitraan masyarakat ini, potensi kehilangan air hanya terjadi melalui penguapan. Terutama limbah pada media dengan fitoremediasi eceng gondok. Namun kondisi ini tidak menjadi hambatan ketersediaan air mengingat pembuangan limbah yang rutin dilakukan. Perlakuan fitoremediasi disajikan pada gambar 3.

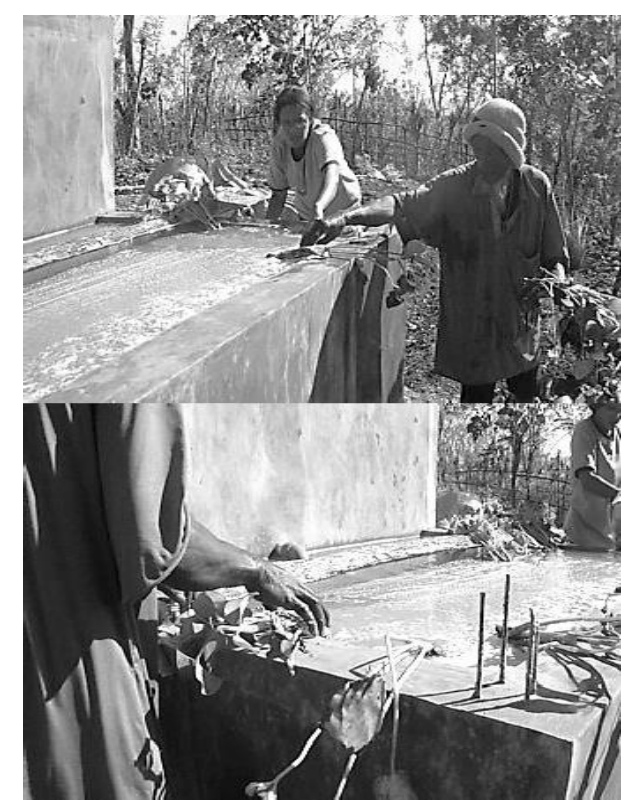

Gambar 3. Fitoremediasi menggunakan tanaman eceng gondok

Kehadiran tanaman air di dalam kolam pengolahan sangat potensial untuk menyaring dan menyerap bahan yang terlarut di dalam limbah. Selain itu tanaman air juga aman, relatif sederhana dan murah. Kemampuan tanaman air, seperti eceng gondok, untuk mengikat bahan-bahan organik dari partikel lumpur membuat tanaman ini dapat digunakan untuk menjernihkan air (Trihadaningrum, 2002).

\section{Pengairan pada Tanaman}

Hasil pengolahan limbah yang dilakukan melalui 2 tahapan dalam bioremediasi bertingkat yaitu perlakuan EM4 pada media 1 dan fitoremediasi pada media 2, dimaksudkan untuk mengurangi pencemaran udara. Sedangkan pada tahapan selanjutnya (fitoremediasi) dimaksudkan agar limbah lebih jernih sehingga mudah dialiri melalui saluran perpipaan. Air pada media 2 perlakuan fitoremediasi eceng gondok yang telah jernih, dialiri ke tandon dan kemudian masuk melalui saluran perpipaan menuju bedeng tanam seperti tertera pada gambar 4 . 

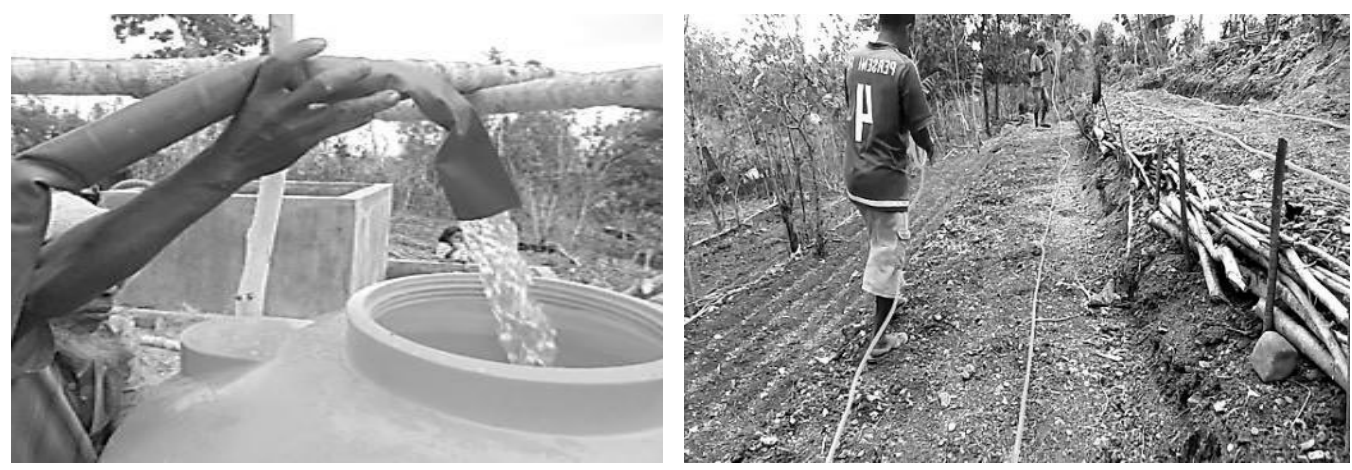

Gambar 4. Irigasi pada tanaman menggunakan limbah dari perlakuan fitoremediasia

\section{Dampak Pelaksanaan Program PKM bagi Kelompok Mitra dan Masyarakat}

Peningkatan bahan baku kedelai akan seiring dengan meningkatnya limbah yang dihasilkan. Kebutuhan kedelai pada industri tahu hingga saat ini mencapai $137 \mathrm{~kg}$ per hari dari sebelumnya sebanyak $40 \mathrm{~kg}$ per hari. Terjadi peningkatan bahan baku sebesar $97 \mathrm{~kg}$. Produksi tahu per hari 440 bungkus tahu (1 bungkus ada 8 irisan) menghasilkan limbah sebanyak 10.000 liter. Dari sebelumnya sebanyak 2 kali per hari pengangkutan limbah ke lahan tani menjadi 4 kali pengangkutan.

Pelaksanaan program kemitraan masyarakat membawa dampak bagi para petani lainnya yang berhasrat meningkatkan produksi tanaman dan ternak untuk menyediakan sendiri lubang penampungan limbah bahkan mereka rela membayar limbah tersebut. Tercatat sebanyak 90 petani yang berdekatan dengan lahan mitra memanfaatkan limbah tersebut. Jumlah pemakai limbah terbanyak terutama untuk budidaya pakan ternak. Umumnya mereka membudidayakan tanaman kinggres untuk pakan sapi.

Meningkatnya pemakaian limbah di lahan, sangat menguntungkan pihak industi tahu. Selama ini pengangkutan dilakukan menggunakan truk pengangkut yang disewakan. Sekali mengangkut Rp. 20.000 x 4 kali = Rp.80.000. Namun saat ini pihak industri menerima bayaran limbah dari beberapa petani hingga mencapai Rp. 100.000 per hari. Petani yang memanfaatkan limbah dengan tujuan pakan ternak dikenakan biaya pengangkutan. Sedangkan petani yang memanfaatkan limbah untuk tujuan budidaya selain pakan ternak tidak dipungut biaya pengangkutan. Perbandingan kondisi sebelum dan sesudah Program Kemitraan Masyarakat (PKM) bagi petani Kelompok Tani Oeputi dan masyarakat disajikan pada tabel 1. 
Jurnal SEMAR Vol. 7 No. 2, 2018 hal. $15-22$

ISSN: 2302-3937 | Copyright (C) LPPM Universitas Sebelas Maret

Homepage: https://jurnal.uns.ac.id/jurnal-semar

\begin{tabular}{|c|c|c|}
\hline Parameter & $\begin{array}{l}\text { Sebelum Program } \\
\text { PKM }\end{array}$ & Sesudah Program PKM \\
\hline $\begin{array}{l}\text { Pembuangan } \\
\text { limbah oleh } \\
\text { kelompok } \\
\text { industri tahu }\end{array}$ & $\begin{array}{l}\text { Dibuang secara } \\
\text { bebas dilahan } \\
\text { pertanian warga. dan } \\
\text { tidak dapat } \\
\text { dimanfaatkan secara } \\
\text { baik. }\end{array}$ & $\begin{array}{l}\text { Pembuangan limbah } \\
\text { menggunakan konsep } \\
\text { bioremediasi dan fitoremediasi. } \\
\text { Sehingga petani merasakan } \\
\text { manfaat limbah tersebut. }\end{array}$ \\
\hline $\begin{array}{l}\text { Lokasi } \\
\text { usaha } \\
\text { petani }\end{array}$ & Pekarangan rumah & Lahan pertanian yang luas \\
\hline $\begin{array}{l}\text { Sistim } \\
\text { pengairan }\end{array}$ & $\begin{array}{l}\text { Sistim pengairan } \\
\text { dilakukan dengan } \\
\text { cara dipikul dan } \\
\text { disiram } \\
\text { menggunakan tangan }\end{array}$ & $\begin{array}{l}\text { Sistim pengairan menngunakan } \\
\text { instalasi irgasi dengan sumbernya } \\
\text { diperoleh dari limbah cair yang } \\
\text { diantar ke lahan }\end{array}$ \\
\hline $\begin{array}{l}\text { Jenis } \\
\text { tanaman } \\
\text { budidaya }\end{array}$ & $\begin{array}{l}\text { Tanaman kol dan } \\
\text { sawi putih }\end{array}$ & $\begin{array}{l}\text { Tanaman cabai, terung, kangkung } \\
\text { dan kacang tanah }\end{array}$ \\
\hline $\begin{array}{l}\text { Jumlah musim } \\
\text { tanam per tahun }\end{array}$ & 1 & $\begin{array}{l}2 \text { (lebih dari } 2 \text { musim untuk } \\
\text { tanaman kangkung) }\end{array}$ \\
\hline $\begin{array}{l}\text { Manfaat } \\
\text { limbah bagi } \\
\text { ternak sapi }\end{array}$ & Belum dimanfaatkan & $\begin{array}{l}\text { Dimanfaatkan untuk budidaya } \\
\text { tanaman (pakan ternak) }\end{array}$ \\
\hline
\end{tabular}

\section{PENUTUP}

Berdasarkan pemaparan seluruh tahapan pelaksanaan dan hasil maka dapat disimpulkan bahwa seluruh target luaran telah dicapai diantaranya: 1) Telah dibangunnya 2 unit media penampung limbah masing-masing berkapasitas 2.500 liter. 2) Pelaksanaan kegiatan pelatihan pengolahan limbah dengan EM4 dan tanaman air pada media tampung yang disediakan telah memberikan wawasan pengetahuan dan keterampilan sehingga petani mampu menerapkan yang ditunjukkan dengan melakukan perbandingan campuran pada tahap pengenceran dan fermentasi secara tepat. 3). Pemanfaatan teknologi pengolahan limbah menjadikan lingkungan lebih baik dan mampu menyediakan kebutuhan irigasi bagi petani. 4) Terjadi peningkatan pendapatan petani kelompok tani Oeputi. 5) Meningkatnya jumlah pemakai limbah terutama pemakai dengan tujuan budidaya pakan ternak. 
Jurnal SEMAR Vol. 7 No. 2, 2018 hal. $15-22$

ISSN: 2302-3937 | Copyright @ LPPM Universitas Sebelas Maret Homepage: https://jurnal.uns.ac.id/jurnal-semar

\section{UCAPAN TERIMA KASIH}

Terima kasih kami haturkan kepada seluruh pihak yang telah membantu pelaksanaan kegiatan pengabdian pada masyarakat diantaranya:

1. Kementerian RISTEK DIKTI yang telah membiayai kegiatan pengabdian melalui Program Kemitraan Masyarakat (PKM) sehingga berjalan lancar dan memberikan manfaat bagi masyarakat.

2. Universitaas Timor dan Lembaga Penelitian dan Pengabdian pada Masyarakat yang memberikan kesempatan kepada tim pengabdi untuk melaksanakan pengabdian di kelurahan Sasi, kecamatan Kefamenanu, kabupaten TTU, propinsi NTT.

3. Masyarakat kelurahan Sasi yang sangat mendukung terlaksananya program kemitraan masyarakat.

\section{DAFTAR PUSTAKA}

BPS Kabupaten Timor Tengah Utara, 2016. Timor Tengah Utara Dalam Angka, Kefamenanu.

Darsono. 2007. Pengolahan Limbah Cair Tahu Secara Anaerob dan Aerob.Jurnal Teknologi Industri, Vol.XI No.1.

Indahwati. 2008. Pengaruh Pemberian Limbah Cair Tahu terhadap Nasrul Hosen, 2012. Adopsi Teknologi Pengolahan Limbah Pertanian Oleh Petani Anggota Gapoktan Puap di Kabupaten Agam Sumatra Barat. Jurnal Penelitian Pertanian Terapan Vol.12. No.2:89-85

Nohong. 2010. Pemanfaatan Limbah Tahu Sebagai Bahan Penyerap Logam Krom, Kadmium dan Besi dalam Air Lindi TPA. Kendari: Jurusan Kimia FMIPA Universitas Haluoleo Kendari Vol. 6 No. 2 Februari 2010

Nugraheni P, Yulinah Trihadaningrum. 2002. Pengaruh Sifat Payau Dan Kesadahan Sumber Air oleh Eceng gondok Jurnal Kimia Lingkungan. Vol.3, No.2. Pertumbuhan Vegetatif Cabai Merah (Capsicum Annuum. L) Secara Hiroponik dengan Metode Kultur Serabut Kelapa. Skripsi. Malang. Program Studi Pendidikan Biologi, Jurusan Pendidikan Matematika dan Ilmu Pengetahuan Alam, Fakultas Keguruan dan Ilmu Pendidikan, Universitas Muhamadyah

Sutrisno,A. Evie., R. Herlina, F. 2015. Fermentasi Limbah Cair Tahu Menggunakan

EM4 sebagai alternatif nutrisi hidroponik dan aplikasi pada sawi hijau. Jurusan Biologi, Fakultas Matematika dan Ilmu Pengetahuan Alam. LenteraBio Vol.4 No.

1. 66-63. Universitas Negeri Surabaya 